\title{
A sustentabilidade na perspectiva de discentes de graduação em Ciências Contábeis: prevalece a lógica oportunista e utilitarista
}

\section{Sustainability in the opinion of undergraduate students in accountancy programs: the opportunist and utilitarian logic prevails}

Sostenibilidad en la perspectiva de los estudiantes de grado en contabilidad: prevalece la lógica oportunista y utilitaria

\section{Annor da Silva Junior}

Doutor em Administração pela Universidade Federal de Minas Gerais (UFMG)

Professor do Departamento de Ciências Contábeis da Universidade Federal do Espírito Santo (UFES)

Endereço: Av. Fernando Ferrari, no 514 - CCJE - Edifício ED6 - Sala 636, Bairro: Goiabeiras

CEP: 29.075-910 - Vitória/ES - Brasil

E-mail: annor.silva@ufes.br

Telefone: (27) 99981-3451

Katia Cyrlene de Araújo Vasconcelos

Doutora em Administração pela Universidade Federal do Espírito Santo (UFES)

Professora do Departamento de Administração da Universidade Federal do Espírito Santo (UFES)

Endereço: Av. Fernando Ferrari, nº 514 - CCJE - Edifício ED6 - Sala 636, Bairro: Goiabeiras

CEP: 29.075-910 - Vitória/ES - Brasil

E-mail: katia.vasconcelos@ufes.br

Telefone: (27) 99608-6703

\section{Vitor Correa da Silva}

Mestre em Ciências Contábeis pela Universidade Federal do Espírito Santo (UFES)

Endereço: Av. Fernando Ferrari, nº 514 - CCJE - Edifício ED6 - Sala 636, Bairro: Goiabeiras

CEP: 29.075-910 - Vitória/ES - Brasil

E-mail: vitor_correa@msn.com

Telefone: (27) 99916-8024

\section{Gabriel Moreira Campos}

Doutor em Ciências Contábeis na Universidade de São Paulo (USP)

Professor do Departamento de Ciências Contábeis da Universidade Federal do Espírito Santo (UFES)

Endereço: Av. Fernando Ferrari, nº 514 - CCJE - Edifício ED6 - Sala 636, Bairro: Goiabeiras

CEP: 29.075-910 - Vitória/ES - Brasil

E-mail: gabriel.campos@ufes.br

Telefone: (27) 99224-0753

Artigo recebido em 01/04/2018. Revisado por pares em 07/09/2018. Reformulado em 30/03/2020. Recomendado para publicação em 15/04/2020 por Carlos Eduardo Facin Lavarda (Editor-Chefe). Publicado em 24/04/2020. 


\title{
Resumo
}

Investigou-se o ponto de vista de discentes de graduação em ciências contábeis acerca da noção de sustentabilidade. Teoricamente, articulou-se os conceitos de sustentabilidade, de moral e de ética e de formação educacional e profissional do contador. Realizou-se uma pesquisa survey, cuja coleta envolveu a triangulação de dados por meio da aplicação de questionários e pesquisa documental. A amostra contou com 285 discentes (36,12\% do tamanho da população) de todos os períodos e turnos do curso. Os resultados revelam que a noção de sustentabilidade predominante na literatura, que pressupõe o tratamento equitativo das dimensões econômica, social e ambiental, não é compartilhada pelos respondentes. Pelo contrário, observou-se a prevalência da dimensão econômica frente as demais. Em parte, esta prevalência está ancorada na lógica oportunista e utilitarista que permeia a formação do contador. Os resultados remetem para a necessidade de se repensar no modelo de educação vigente, rumo a uma lógica sustentável.

Palavras-chave: Sustentabilidade; Moral e Ética; Formação do Contador; Comportamento Esperado; Comportamento Efetivo

\begin{abstract}
It was investigated the opinion of students in the Accountancy undergraduate program regarding the notion of sustainability. Theoretically, the concepts of sustainability, morals and ethics and the accountant educational and professional training were articulated. A survey was carried out and data collection involved the triangulation by combining the application of a questionnaire and documentary research. The sample consisted of 285 students (36.12\% of the population size) of all periods and shifts of the course. The results reveal that the notion of sustainability predominant in the literature, which presupposes the equitable treatment of the economic, social and environmental dimensions, is not shared by the respondents. Contrariwise, it was observed the prevalence of the economic dimension in relation to the other dimensions. In part, this prevalence is anchored in the opportunist and utilitarian logic that permeates the accountant education. The results point to the need of rethinking the current education model towards a sustainable logic.
\end{abstract}

Keywords: Sustainability; Morals and Ethics; Accountant Education; Expected Behavior; Actual Behavior

\section{Resumen}

Se investigó el punto de vista de los estudiantes universitarios de ciencias contables sobre la noción de sostenibilidad. Teóricamente, se articuló los conceptos de sostenibilidad, moral y ética y formación educativa y profesional del contador. Se realizó una encuesta, cuya recopilación involucró la triangulación de datos mediante la aplicación de cuestionarios y la investigación documental. La muestra incluyó 285 estudiantes (36.12\% del tamaño de la población) de todos los períodos y turnos del curso. Los resultados revelan que los encuestados no comparten la noción de sostenibilidad que prevalece en la literatura, que presupone un tratamiento equitativo de las dimensiones económica, social y ambiental. Por el contrario, se observó la prevalencia de la dimensión económica sobre las demás. En parte, esta prevalencia está anclada en la lógica oportunista y utilitaria que impregna la formación del contador. Los resultados se refieren a la necesidad de repensar el modelo actual de educación, hacia una lógica sostenible.

Palabras clave: Sostenibilidad; Moral y Ética; Formación Contable; Comportamiento Esperado; Comportamiento Efectivo

\section{Introdução}

Pretendeu-se neste artigo investigar o ponto de vista de discentes de ciências contábeis de uma universidade pública brasileira sobre a noção de sustentabilidade. Para isso, abordou-se três temas centrais: moral e a duplicidade tipicamente brasileira; formação educacional e profissional 
do contador; e sustentabilidade.

A primeira temática abordada neste estudo diz respeito à noção de moral, de uma forma geral e, à noção da duplicidade moral que caracteriza o comportamento típico do brasileiro, em específico (SROUR, 1994; ARANHA; MARTINS, 2005; PEDRO, 2014). Conforme destaca Aranha e Martins (2005), a moral diz respeito aos valores, costumes, e normas de conduta específicas de uma determinada sociedade. A noção de moral é considerada central na análise sociológica por estar associado à noção de ética e pelo fato destes dois conceitos (moral e ética) admitirem que os valores representam o seu aspecto central (ARANHA; MARTINS, 2005; PEDRO, 2014). Considerando que o valores são usados para caracterizar grupos culturais, sociedades e indivíduos, bem como para mapear as mudanças ao longo do tempo e explicar as bases motivacionais de atitudes e de comportamentos (SCHWARTZ, 2012), as noções de moral e de ética assumem papel central no direcionamento do comportamento social e individual.

Ao se analisar a noção de moral, observa-se que se trata de um conceito abstrato (PEDRO, 2014), mas que possui uma maior concretude quando contextualizado junto a um estado nacional. Srour (1994) defende que no contexto brasileiro coexiste uma dupla moral social: (1) uma moral da integridade, considerada oficial, edificante e convencional; e (2) uma moral do oportunismo, que é oficiosa, pragmática e interesseira. Esta duplicidade moral tem potencial para explicar o comportamento do brasileiro em distintas dimensões da vida social, como por exemplo, no processo de formação educacional e profissional e na postura diante dos desafios relacionados à sustentabilidade, os dois outros temas abordados nesta pesquisa.

No contexto brasileiro, a atividade profissional em ciências contábeis é regulamentada por legislação federal que institui requisitos fundamentais para o exercício profissional, como por exemplo, a diplomação em curso de bacharelado em ciências contábeis e o registro no Conselho Regional de Contabilidade (CRC) vinculado ao Conselho Federal de Contabilidade (CFC). A atividade profissional do contador é regulamentada pelo Decreto-Lei $n^{\circ}$ 9.295, de 27 de maio de 1946 que, entre outras providências, cria o Conselho Federal de Contabilidade (CFC) e define as atribuições do contador (MIRANDA; MIRANDA; ARAÚJO, 2013; BRASIL, 1946).

Essa norma jurídica faz referência à necessidade de obtenção de diploma de bacharelado em curso de graduação em ciências contábeis devidamente reconhecido pelo Ministério da Educação (MEC) para que se possa exercer a profissão de contador (BRASIL, 1946). O MEC, ao exercer o papel regulador da educação superior edita normas jurídicas como é o caso das Diretrizes Curriculares Nacionais (DCN) que, no caso específico das ciências contábeis, foi regulamentado por meio da Resolução CNE/CES n ${ }^{\circ}$ 10/2004 (CNE, 2004). Estas diretrizes estabelecem as orientações para que as Instituições de Educação Superior (IES) possam definir em seus Projetos Pedagógicos de Curso (PPC) tópicos específicos, como por exemplo, os objetivos do curso, o perfil profissional, os componentes curriculares, entre outros.

Segundo aponta Laffin (2015), a concepção de formação adotada nas DCN está ancorada no desenvolvimento de competências e de habilidades, o que o autor denomina de "pedagogia das competências". Esta pedagogia desenvolve um tipo de formação voltada à lógica do mercado com enfoque técnico e operacional centrado no fazer. Este tipo de formação desloca o processo pedagógico de uma forma de ensino baseado em saberes disciplinares para uma forma de ensino ancorada em competências específicas de produção (LAFFIN, 2015).

Ao abordarem o enfoque técnico e operacional no curso de ciências contábeis, Pires, Ott e Damacena (2010) afirmam que as IES brasileiras têm a responsabilidade de formar profissionais dotados das competências necessárias para atuar nas mais diversas áreas da contabilidade, tais como: auditoria, finanças, controladoria, etc. Esta formação educacional tem como finalidade suprir as demandas do mercado de atuação profissional do contador.

Esta perspectiva de formação baseada na "pedagogia das competências" (LAFFIN, 2015) parece alinhar-se com a noção de contabilidade apontada por Iudícibus, Martins e Carvalho (2005). Para os autores, a contabilidade consiste em um corpo de conhecimento determinante para a 
formação de agentes decisórios em diferentes níveis que tem como fundamento os fatos econômicos e financeiros das organizações que são captados e processados por meio de metodologia própria, permeada pela racionalidade científica (IUDÍCIBUS; MARTINS; CARVALHO, 2005).

Para Laffin (2015) este tipo de formação baseada na "pedagogia das competências", além de ser restritiva em função das características de racionalidade técnica, tem como implicação o comprometimento de uma sólida formação científica e colaborativa em termos do desenvolvimento social. Autores como Rodrigues et al. (2017), Laffin (2015), Miranda, Casa Nova e Cornacchione Júnior (2012) e Tinoco e Robles (2006) alertam para os riscos e limitações de uma formação eminentemente técnica e operacional na contabilidade e para a necessidade de superar as fronteiras conceituais e disciplinares, como forma de lidar com a complexidade do contexto contemporâneo e com as preocupações socioambientais e de sustentabilidade.

A sustentabilidade e o desenvolvimento sustentável representam temas e desafios centrais da atualidade, alcançando status de relevância no meio acadêmico e empresarial (RODRIGUES et al., 2017; BELL; MORSE, 2008). As discussões em torno da sustentabilidade ganharam repercussão internacional com a apresentação do Relatório Brundtland - Nosso Futuro Comum”, publicado em 1987. Este relatório apresentou a definição de desenvolvimento sustentável como sendo "aquele que atende às necessidades do presente sem comprometer a possibilidade de as gerações futuras atenderem as suas próprias necessidades" (COMISSÃO MUNDIAL SOBRE MEIO AMBIENTE E DESENVOLVIMENTO, 1991, p. 46).

A despeito de todo alcance e repercussão, esta definição de desenvolvimento sustentável tem sido questionada por sua imprecisão e por representar um discurso liberal e redentor. Além disso, algumas críticas tratam da natureza complexa e ambígua desta definição, bem como de seu caráter coercitivo. Este caráter coercitivo, desconsidera as possibilidades de existência de tensões decorrentes na natureza complexa e multifacetada da sustentabilidade corporativa (HANN et al., 2015; MUNCK; SOUZA, 2011; CIEGIS; RAMANAUSKIENE; MARTINKUS, 2009; MEBRATU, 1998).

Apesar das críticas e controvérsias, parece haver na literatura sobre a sustentabilidade e o desenvolvimento sustentável, concordância entre os autores em pelo menos dois pontos centrais. Primeiro, no entendimento que o desenvolvimento sustentável representa orientação para o futuro do progresso humano, ao articular três dimensões, quais sejam, a econômica, a social e a ambiental (ou ecológica) (MUNCK; SOUZA, 2011; OSORIO; LOBATO; CASTILLO, 2005; LÉLÉ, 1991). A articulação destas três dimensões ficou conhecida como o triple bottom line - TBL, conceito cunhado por Elkington (2012).

O segundo ponto, refere-se ao entendimento de que a sustentabilidade é um fenômeno social relevante para as organizações e para a sociedade. Nesse sentido, pela via de discussões relacionadas ao desenvolvimento sustentável é possível fomentar o interesse das organizações em alcança-lo por meio de dois caminhos: (1) o do imperativo legal com a regulação e a imposição; e (2) da proatividade ou do voluntarismo organizacional (MUNCK; SOUZA, 2011). Neste caso, tem-se de um lado, o determinismo e, de outro, o voluntarismo, como direcionadores do posicionamento das organizações frente ao desenvolvimento sustentável.

Ao considerar a perspectiva do voluntarismo, assume-se que a sustentabilidade e o desenvolvimento sustentável decorrem de atos de gestão (agir) organizacional (MUNCK; SOUZA, 2011). Neste caso, este ato de gestão requer uma estrutura de "agires" organizacional (MUNCK; SOUZA, 2011) que envolve, entre outros fatores, o inter-relacionamento e a interdependência entre a administração e a contabilidade. Isso pelo fato, da contabilidade ser a área da organização responsável pelo processo de gerar, analisar, preparar, interpretar e comunicar informações oriundas dos fatos que alteram a situação patrimonial e financeira que servem como fundamentos para a tomada de decisões gerenciais nas organizações (TINOCO; ROBLES, 2006; IUDÍCIBUS; MARTINS; CARVALHO, 2005; MARTIN, 2002). 
Ao olhar sob esse prisma, Tinoco e Robles (2006) apontam para a centralidade da contabilidade como fornecedora de informações para a tomada de decisões voltadas para a sustentabilidade. Os autores defendem que é papel da contabilidade superar os desafios da sustentabilidade e contribuir para que as organizações possam se adaptar aos novos critérios de desenvolvimento em bases sustentáveis.

Para que a contabilidade seja efetiva nesse processo, defende-se neste estudo, que a formação dos discentes de ciências contábeis exerce influência direta na forma como o contador compreende a sustentabilidade. Ao assumir este entendimento, este estudo volta-se para a investigação do ponto de vista dos discentes de ciências contábeis sobre a noção de sustentabilidade, para definir o seguinte problema de pesquisa: Qual é o ponto de vista de discentes de graduação em ciências contábeis sobre a noção de sustentabilidade? Com base nessa questão, definiu-se como objetivo geral o de identificar o ponto de vista de discentes de graduação em ciências contábeis sobre a noção de sustentabilidade. Para alcançar o objetivo central proposto, realizou-se uma pesquisa survey de natureza descritiva e quantitativa (BABBIE, 2005) junto aos discentes de ciências contábeis de uma universidade pública federal localizada na região sudeste do Brasil, com dados coletados por meio de pesquisa documental e aplicação de questionários. Os dados foram analisados por meio de procedimentos estatísticos operacionalizados pelo software SPSS versão 22

Estruturou-se este artigo em quatro seções além desta introdução. Na segunda seção apresenta-se o referencial teórico que fundamenta a pesquisa. Na terceira seção apresentam-se os procedimentos metodológicos que nortearam o processo de coleta e de análise dos dados. Na seção seguinte apresenta-se e discute-se os resultados da pesquisa. Por fim, na quinta e última seção, são apresentadas as conclusões.

\section{Referencial Teórico}

Estruturou-se esta seção em três subseções. Na primeira subseção discute-se a abordagem teórica em torno da dupla moral social tipicamente brasileira (SROUR, 1994). A segunda subseção é dedicada à sustentabilidade e ao desenvolvimento sustentável (CIEGIS; RAMANAUSKIENE; MARTINKUS, 2009). Por fim, na última subseção aborda-se a questão da formação do contador e como a sustentabilidade é tratada neste contexto educacional.

\subsection{A dupla moral social brasileira: moral da integridade e moral do oportunismo}

Antes de abordar a dupla moral social (SROUR, 1994) entende-se ser necessário demarcar as diferenças conceituais em torno das noções de moral e de ética. No entendimento de Pedro (2014), a moral consiste em um conjunto de valores, princípios, costumes e normas de conduta específicos de uma determinada sociedade ou cultura. Já a ética se dedica à reflexão a respeito das noções e dos princípios que fundamentam a vida moral, reflexão esta que, por ser livre, tem potencial para seguir as mais diversas direções (ARANHA; MARTINS, 2005).

Ainda para Pedro (2014, p. 486), enquanto a noção de moral "é eminentemente prática e voltada para a ação concreta e real, para um certo saber fazer prático-moral e para a aplicação de normas morais consideradas válidas por todos os membros de um determinado grupo social"; a ética, por sua vez é "essencialmente especulativa, não se devendo dela exigir um receituário quanto a formas de viver com sucesso, dado que se preocupa, sobretudo, com a fundamentação da moral". Esse entendimento, parece indicar que, enquanto a moral é coletiva, a noção de ética é um julgamento valorativo individual norteado pela moral coletiva, estabelecendo com isso uma relação de interdependência e causalidade circular entre a moral e a ética (PEDRO, 2014). Feita esta demarcação, é possível avançar com a discussão acerca da dupla moral social.

Ao analisar os processos sociais tipicamente brasileiros, Srour (1994) aponta para a 
existência de uma duplicidade moral social que abrange a moral da integridade e a moral do oportunismo. Segundo Srour (1994) essa dupla moral social acarreta em uma "ambiguidade ética" que envolve, de um lado a ética do princípio e, de outro, a ética de finalidade. Neste caso, tanto a dupla moral quanto a ambiguidade ética, orientam o comportamento social brasileiro.

A moral da integridade é vista como uma moralidade oficial, edificante e convencional que compõe uma retórica pública dominante difundida em escolas, nas igrejas e na mídia. Esta moral tem como valores a lealdade, a idoneidade, a honestidade, o compromisso com a retidão e o respeito à verdade. Esses valores da moral da integridade, desenham o perfil do homem de caráter, decente de digno, confiável e cumpridor de suas obrigações. Esta moral é sustentada pela abordagem ética do princípio, uma deontologia que justifica os cursos de ação por meio dos valores ou dos princípios neles implícitos (SROUR, 1994).

A moral do oportunismo é tida como moralidade oficiosa, pragmática, interesseira e dissimuladamente praticada com intuitos particulares ou privados, celebrada pela esperteza de seus procedimentos. A moral do oportunismo que se expressa por procedimentos cínicos como o jeitinho, a falta de escrúpulo, o vale-tudo, o clientelismo e o fisiologismo, tem como valores o egoísmo, a ânsia pelo enriquecimento rápido, a consagração da "esperteza" e a legitimidade pelo máximo proveito pessoal. A abordagem ética que sustenta esta moral é a ética de finalidade (teleologia), perspectiva cujo os cursos de ação são justificados pelos propósitos do agente, ou seja, a ação estará justificada caso realize a finalidade pretendida (SROUR, 1994).

Assim, de acordo com Srour (1994) a dinâmica social brasileira articula, por um lado, o posicionamento ideológico-filosófico voltado para a dimensão pública que é ancorado na moral da integridade e na ética do princípio e, por outro, um posicionamento voltado para a dimensão privada suportado pela moral do oportunismo e pela ética de finalidade. Com isso, é possível observar uma dualidade de posicionamentos que se materializa no comportamento esperado e no comportamento efetivo. O primeiro fundamentado no "discurso do politicamente correto" (CABRAL, 2013) voltado para a dimensão pública, e o segundo, fundamentado em interesses individuais relativos à dimensão privada.

Empiricamente, esse dupla moral social típica brasileira (SROUR, 1994) tem sido utilizada no desenvolvimento de pesquisas científicas, inclusive no campo de estudos das ciências contábeis. Por exemplo, Facci (2002) articulou aspectos inerentes à atuação ética das organizações e os desafios constantes para a controladoria. Paletta (2016) analisou o papel do educador na formação do profissional da informação e os desafios da cidadania responsável, destacando a ética e suas relações com a informação, o conhecimento e a criatividade. Silva Junior et al. (2017) investigaram a noção de moral e de ética para discentes de ciências contábeis. Seguindo esta mesma linha, articulou-se neste estudo a perspectiva da dupla moral social brasileira (SROUR, 1994) com os temas sustentabilidade e formação educacional em ciências contábeis.

\subsection{Sustentabilidade e desenvolvimento sustentável}

Desde que o conceito de desenvolvimento sustentável ganhou notoriedade internacional com a apresentação do Relatório Brundtland - Nosso Futuro Comum" em 1987, várias iniciativas surgiram para definir sustentabilidade e desenvolvimento sustentável (MUNCK; SOUZA, 2011; CIEGIS; RAMANAUSKIENE; MARTINKUS, 2009). Estas diversas tentativas tiveram como consequência as possíveis dificuldades de entendimento acerca do conceito de desenvolvimento sustentável, bem como múltiplos significados dependendo da literatura utilizada (PIERANTONI, 2004).

Por exemplo, ao analisarem os conceitos de sustentabilidade, Osorio, Lobato e Castillo (2005) identificaram duas principais vertentes: (1) a normativa que orienta para o que deveria ser feito; e (2) a positiva que demostra a realidade, ou seja o que é feito de fato. Segundo os autores, a vertente normativa se preocupa com os acordos e as propostas de caráter institucional que se 
propõe a indicar o comportamento prescrito para o alcance do desenvolvimento sustentável. Já a vertente positiva orienta-se por meio de análises e procedimentos científicos, ancorados em áreas do conhecimento como a economia, a ecologia e a filosofia sem, contudo, chegar a um acordo sobre os caminhos para se alcançar o desenvolvimento sustentável.

A despeito da diversidade conceitual e das diferentes vertentes e perspectivas sobre a sustentabilidade e o desenvolvimento sustentável (MUNCK; SOUZA, 2011; CIEGIS; RAMANAUSKIENE; MARTINKUS, 2009; OSORIO; LOBATO; CASTILLO, 2005; MEBRATU, 1998) adota-se neste estudo a noção de sustentabilidade apontada por Ciegis, Ramanauskiene e Martinkus (2009). Segundo esses autores, a noção de sustentabilidade está associada, num sentido mais amplo, à equidade na distribuição das possibilidades de desenvolvimento entre o presente e as futuras gerações.

Em outros termos, o desenvolvimento sustentável pode ser definido como uma melhor qualidade de vida do presente e das futuras gerações. Ciegis, Ramanauskiene e Martinkus (2009) complementam ainda que o desenvolvimento sustentável não envolve uma escolha entre a proteção ambiental e o progresso social. Está relacionado com um esforço maior para o desenvolvimento econômico e social que seja compatível com a proteção ao meio ambiente. Com isso, o desenvolvimento sustentável envolve três dimensões fundamentais (econômica, social e ambiental), que são interdependentes e formam o TBL (ELKINGTON, 2012).

No entendimento de Munck e Souza (2011) ao se aliar economia e meio ambiente (ecologia) o desenvolvimento sustentável é aceito como um objetivo e passa a representar um meio para o progresso humano e social, por meio de uma abordagem integrativa e inclusiva que envolve as gerações atuais e futuras. Conforme apontam Vasconcelos, Silva Junior e Silva (2013), Senge et al. (2009) e Almeida (2008), esta abordagem integrativa e inclusiva leva em consideração um modelo baseado em uma governança tripolar que, entre outros aspectos, implica em trocas dinâmicas entre os atores econômicos e sociais com vistas ao alcance de equilíbrio entre os objetivos e resultados financeiros, sociais e ambientais, que caracterizam o modelo sustentável.

\subsection{Formação do contador e a sustentabilidade}

A formação superior em ciências contábeis e, a consequente postura profissional em relação às questões socioambientais, têm ocupado significativo espaço na literatura sobre educação contábil (LEE, 1989; GRAY; BEBBINGTON; McPHAIL, 1994; HUMPHREY; LEWIS; OWEN, 1996; MATHEWS, 2001; GRAY; COLLISON, 2002; LAFFIN, 2015). Neste contexto, pelo menos dois aspectos têm sido abordados com frequência: (1) a necessidade de mudança estrutural em uma formação que privilegia aspectos técnicos em detrimento das questões humanas e sociais (LEE, 1989; MATHEWS, 2001; LAFFIN, 2015); e (2) os questionamentos sobre se o status quo do processo de ensino e aprendizagem da área resulta em efetiva contribuição dos egressos para o desenvolvimento humano e social (HUMPHREY; LEWIS; OWEN, 1996; MATHEWS, 2001; GRAY; COLLISON, 2002; LAFFIN, 2015).

Na literatura internacional, estudos clássicos como os de Lee (1989) e de Zeff (1989) podem ser considerados fundamentais na abordagem de questões relativas à educação e a prática contábil e os trabalhos de Gray, Bebbington e McPhail (1994), Humphrey, Lewis e Owen (1996), Mathews (2001) e Gray e Collinson (2002) como seminais na abordagem de questões socioambientais no âmbito dos cursos de ciências contábeis. Na literatura nacional o interesse por discutir a formação educacional nos cursos de graduação em ciências contábeis e a abordagem de questões socioambientais é mais recente e voltada para análise do processo de ensino e aprendizagem e as adequações à regulamentação de educação superior brasileira por parte do MEC (MIRANDA; MIRANDA; ARAÚJO, 2013; SILVA; REGO, 2014; SILVA JUNIOR et al., 2017).

No Brasil, tanto o processo de formação educacional em nível superior quanto a atuação profissional em ciências contábeis tem como fundamento, pelo menos três eixos complementares: 
(1) a regulamentação da oferta de cursos por meio das DCN (CNE, 2004) e da atuação profissional por meio de legislação federal (BRASIL, 1946); (2) as DCN de ciências contábeis que estabelecem padrões para que as IES ofertem o curso (MIRANDA; MIRANDA; ARAÚJO, 2013; CNE, 2004); e (3) a atuação das IES que consiste na forma como o curso é ofertado segundo às próprias DCN (PIRES; OTT; DAMACENA, 2010). Na articulação destes três eixos, cabem às IES o papel de formar profissionais dotados de competências e habilidades que os permitam a atuar nas mais diversas áreas da contabilidade, seja na auditoria, nas finanças, na controladoria, contabilidade fiscal, entre outras (RAIA; MELZ, 2011; PIRES; OTT; DAMACENA, 2010; SOUZA et al., 2008).

No entendimento de Laffin (2015) a orientação pedagógica que permeia as DCN de ciências contábeis é a "pedagogia das competências". Esta pedagogia tem como foco privilegiar a formação técnica e negligenciar a formação científica e colaborativa em termos do desenvolvimento social. Esta orientação tecnicista, que também se observa no contexto internacional (LEE, 1989; MATHEWS, 2001), foi identificada por Padoan e Clemente (2006) ao realizar estudo que analisou a interdisciplinaridade no ensino da contabilidade que concluiu que a educação contábil tinha de fato um viés tecnicista.

Em parte, o viés tecnicista presente na formação contábil (LAFFIN, 2015; PADOAN; CLEMENTE, 2006) possui relação com três outros aspectos relativos à formação educacional e à atividade profissional. Estes três aspectos são: (1) o caráter eminentemente utilitarista presente na disciplina contábil (IUDÍCIBUS; MARTINS; CARVALHO, 2005); (2) as influências que a teoria positiva da contabilidade (WATTS; ZIMMERMAN, 1986) exercem sob a formação de discentes de ciências contábeis; e, (3) a perspectiva legalista inerente a atividade profissional do contador (MIRANDA; MIRANDA; ARAÚJO, 2013).

Diante deste cenário que caracteriza a formação educacional e a atuação profissional em ciências contábeis, Laffin (2015) defende que é necessário repensar a "pedagogia das competências" e este viés tecnicista. Segundo Laffin (2015), o desafio é alcançar uma formação contábil que favoreça uma perspectiva mais colaborativa com o desenvolvimento social. Uma das possibilidades para alcançar esta perspectiva é por meio da inserção no currículo dos cursos de ciências contábeis disciplinas que abordem questões socioambientais.

De acordo com Motke et al. (2016) a educação voltada para a abordagem de questões socioambientais e relativas à sustentabilidade envolve um processo de sensibilização que, no âmbito da educação superior, requer o desenvolvimento de políticas educacionais que incorpore tal temática nas disciplinas tradicionais, propiciando, com isso, mudanças conceituais, valorativas e culturais em relação à sustentabilidade. A despeito da relevância da temática e do reconhecimento por parte de docentes e de discentes, Carvalho et al. (2010) destacam que a inserção de conteúdos socioambientais nos cursos de ciências contábeis ainda é tímida.

Conforme apontam Tinoco e Robles (2006) as recentes mudanças no universo corporativo tem provocado um movimento de ampliação de escopo na área contábil para além das informações econômicas e financeiras. Esta ampliação de escopo alcança a divulgação de informações socioambientais, fazendo com que haja uma maior aproximação da contabilidade com os temas sustentabilidade e desenvolvimento sustentável (TINOCO; ROBLES, 2006). Com isso, a contabilidade se torna capaz de exercer sua função social em termos da evidenciação das informações relativas aos impactos sociais e ambientais causados pelas entidades (MACIEL et al., 2009)

\section{Método}

Antes de apresentar os aspectos metodológicos, destacamos que o estudo aqui apresentado faz parte de um projeto de pesquisa mais amplo que articulou os conceitos de ética, responsabilidade social corporativa (RSC) e sustentabilidade para investigar o ponto de vista de 
discentes brasileiros dos cursos de graduação em administração e em ciências contábeis e de discentes de pós-graduação (MBA) na área de negócios. No projeto mais amplo foram coletados 1.882 questionários válidos, sendo que 1.514 foram aplicados junto aos discentes de graduação e 368 aplicados ao discentes de pós-graduação.

Metodologicamente, a pesquisa aqui apresentada se caracteriza como um estudo descritivoquantitativo, por meio do método de pesquisa survey (BABBIE, 2005). Os dados foram coletados por meio de triangulação do tipo "within method", que poderia ser traduzido literalmente para o português como "dentro do método" (DENZIN, 1989). Segundo Denzin (1989), este tipo de triangulação consiste na utilização de mais de um procedimento metodológico para coleta de dados no âmbito de um método de pesquisa específico. No caso deste estudo, a triangulação "within method", ocorreu no âmbito de um estudo descritivo-quantitativo cujo método de pesquisa foi o survey (BABBIE, 2005) com dados coletados por meio de pesquisa documental e aplicação de questionário.

Conforme destaca Jick (1979), a triangulação "within method" em uma pesquisa survey permite a articulação entre escalas de mensuração e outras fontes de informações tendo como foco o mesmo constructo. Seguindo esse entendimento apontado por Jick (1979), neste estudo confrontou-se (1) a opinião dos discentes sobre a sustentabilidade, mensurada por meio de questionário; com (2) informações presentes no PPC de ciências contábeis, em documentos da IES que oferta o curso de ciências contábeis e na legislação educacional, todos coletados por meio de pesquisa documental, para investigar o constructo noção de sustentabilidade sob o ponto de vista dos discentes vinculados ao curso. A Figura 1 apresenta de forma gráfica o procedimento de triangulação "within method" (DENZIN, 1989; JICK, 1979) utilizado na pesquisa.

Figura 1 - Procedimento de triangulação "within method"

\begin{tabular}{|c|c|}
\hline Procedimentos de Coleta de Dados & Conteúdo \\
\hline \multirow[t]{2}{*}{ 1. Pesquisa documental } & Documentos Normativos \\
\hline & Documentos Institucionais \\
\hline
\end{tabular}

$\begin{array}{ll}\text { 2. Questionário } & \begin{array}{l}21 \text { afirmativas } \\ \text { Bloco 2: Ponto de vista dos discentes } \\ \text { sobre sustentabilidade } \\ \text { (42 afirmativas que utilizam } \\ \text { escala de Likert de cinco } \\ \text { pontos do tipo verbal) }\end{array} \begin{array}{r}7 \text { afirmativas de cada uma das } 3 \\ \text { dimensões do TBL e diferentes } \\ \text { stakeholders caracterizando o } \\ \text { comportamento esperado }\end{array} \\ 21 \text { afirmativas } \\ \begin{array}{r}\text { afirmativas de cada uma das } 3 \\ \text { dimensões do TBL e diferentes } \\ \text { stakeholders caracterizando o } \\ \text { comportamento efetivo }\end{array}\end{array}$

Fonte: Elaborado pelos autores.

Segundo Mogalakwe (2006), a pesquisa documental se caracteriza pela utilização de fontes documentais na pesquisa social. No presente estudo a pesquisa documental foi realizada junto a dois conjuntos de documentos, considerados como complementares: (1) documentos normativos tais como (1.1) a Lei $\mathrm{n}^{\circ}$ 9.394/1996 (BRASIL, 1996) que estabeleceu as diretrizes e bases para a educação nacional, (1.2) o Decreto-Lei no 9.295/1946 (BRASIL, 1946) que, entre outros aspectos definiu as atribuições do contador, e (1.3) a Resolução CNE/CES no 10/2004 (CNE, 2004) que criou as DCN para o curso de ciências contábeis; e (2) documentos institucionais da IES e do curso 
dos quais destacam-se, (2.1) os indicadores institucionais, (2.2) o PPC de ciências contábeis que contém todas as informações relativas ao curso, como por exemplo, objetivo do curso, o perfil do egresso, estrutura curricular, corpo docente, capacidade instalada, entre outras; e (2.3) os sites institucionais da IES e do curso. A análise destes dois conjuntos de documentos, permitiu analisar a perspectiva legalista presente no processo de formação educacional e na atividade profissional do contador (MIRANDA; MIRANDA; ARAÚJO, 2013).

Para facilitar o entendimento do leitor em relação à utilização da pesquisa documental, nas próximas seções e/ou subseções do artigo foram utilizados códigos que iniciam com as letras PD seguido por uma extensão que localiza o tipo de documento utilizado. O Quadro 1 apresenta estes códigos.

Quadro 1 - Códigos da pesquisa documental (PD)

\begin{tabular}{|l|l|l|}
\hline Tipo & Documentos & Código \\
\hline \multirow{2}{*}{$\begin{array}{l}\text { Nocumentos } \\
\text { Normativos }\end{array}$} & Lei $^{\circ}$ 9.394/1996 (BRASIL, 1996) & PD-N1 \\
\cline { 2 - 3 } & Decreto-Lei no 9.295/1946 (BRASIL, 1946) $^{\circ}$ & PD-N2 \\
\cline { 2 - 3 } & Resolução CNE/CES n ${ }^{\circ}$ 10/2004 (CNE, 2004) & PD-N3 \\
\hline \multirow{2}{*}{$\begin{array}{l}\text { Documentos } \\
\text { Institucionais }\end{array}$} & Indicadores institucionais & PD-I1 \\
\cline { 2 - 3 } & PPC de ciências contábeis & PD-I2 \\
\cline { 2 - 3 } & Sites institucionais da IES e do curso & PD-I3 \\
\hline
\end{tabular}

Fonte: Elaborado pelos autores.

O questionário foi desenvolvido, submetido a pré-teste e validado especificamente para esta pesquisa. O pré-teste foi realizado presencialmente junto à duas turmas de programas de pósgraduação stricto sensu em ciências contábeis e em administração, e contou com a participação de 21 discentes. A opção por realizar o pré-teste junto a este público, se deu pelo fato de a maioria dos discentes ter formação básica em ciências contábeis e em administração e ter concluído a graduação nos últimos dois anos, qualificando-se para participar do pré-teste. Como resultado do pré-teste, alguns ajustes pontuais foram realizados no questionário para torna-lo mais compreensível aos respondentes. Destaca-se que os participantes do pré-teste não foram incluídos na amostra que efetivamente participou da pesquisa.

Para a elaboração do questionário foram considerados os conceitos de sustentabilidade e de desenvolvimento sustentável (CIEGIS; RAMANAUSKIENE; MARTINKUS, 2009); as três dimensões do TBL, quais sejam: econômica, social e ambiental (ELKINGTON, 2012); as vertentes normativa e positiva relacionadas ao conceito de sustentabilidade identificadas por Osorio, Lobato e Castillo (2005) e um conjunto de stakeholders (PURNELL; FREEMAN, 2012). Ademais, para a construção do questionário, considerou-se a lógica da duplicidade moral tipicamente brasileira (SROUR, 1994), ou seja, o comportamento esperado das pessoas (moral da integridade) e o comportamento efetivo (moral do oportunismo).

Destaca-se neste estudo a presença de alinhamento entre as vertentes normativa e positiva do conceito de sustentabilidade (OSÓRIO; LOBATO; CASTILHO, 2005) e a dupla moral social brasileira (SROUR, 1994). Isso pelo fato de que tanto a vertente normativa da sustentabilidade quando a moral da integridade possui orientação prescritiva que norteia o comportamento esperado. Do mesmo modo que a vertente positiva da sustentabilidade e a moral do oportunismo são orientados para o que de fato é feito para o alcance do desenvolvimento sustentável em termos práticos, norteando o comportamento efetivo.

O questionário foi composto por duas partes, sendo que a primeira se dedicou a identificar o perfil sociodemográfico dos respondentes, e a segunda estava relacionada com os objetivos da pesquisa. Esta segunda parte foi composta por 42 afirmativas em escala Likert de cinco pontos do tipo verbal (COSTA; ORSINI; CARNEIRO, 2018), sendo que os pontos 1 e 2 caracterizam a discordância total e discordância respectivamente; os pontos 4 e 5 caracterizam a concordância e a concordância total; e a ponto 3 (médio) caracteriza um ponto nulo em que não há a discordância 
e/ou a concordância.

Das 42 afirmativas, 21 caracterizavam o comportamento esperado e 21 caracterizavam o comportamento efetivo. Cada grupo de 21 afirmativas era composto por 7 afirmativas de cada uma das três dimensões do TBL (ELKINGTON, 2012). Ressalta-se também que cada uma dessas 7 afirmativas estava relacionada a diferentes stakeholders (PURNELL; FREEMAN, 2012), quais sejam: acionistas, empregados, fornecedores, consumidores, concorrentes, sociedade e meio ambiente.

Considerando que o questionário possui 42 afirmativas e, por uma questão de limitação de espaço no texto, optou-se, em caráter ilustrativo, ser conveniente detalhar como foi a elaboração de duas afirmativas e sua fundamentação teórica, sendo que (1) uma é relativa à vertente normativa da sustentabilidade (OSÓRIO; LOBATO; CASTILHO, 2005) e à moral da integridade (SROUR, 1994), ou seja ao comportamento esperado; e (2) outra uma é relativa à vertente positiva da sustentabilidade (OSÓRIO; LOBATO; CASTILHO, 2005) e à moral do oportunismo (SROUR, 1994), ou seja ao comportamento efetivo.

Por uma questão de alinhamento ao TBL (ELKINGTON, 2012) e ao conjunto de stakeholders (PURNELL; FREEMAN, 2012) selecionou-se duas afirmativas da dimensão econômica e relacionadas ao stakeholder acionista, são elas: (1) afirmativa 1: o lucro de uma organização deve sempre ser distribuído de forma equitativa entre os acionistas, os trabalhadores, a sociedade e o meio ambiente; e (2) afirmativa 16: a prática organizacional cotidiana privilegia a remuneração aos acionistas em detrimento de outras partes interessadas, como por exemplo, os trabalhadores, a sociedade e o meio ambiente. Destaca-se que a afirmativa 1 refere-se ao comportamento esperado e que a afirmativa 16 refere-se ao comportamento efetivo.

Como pode-se observar, a afirmativa 1 contempla a noção de sustentabilidade que pressupõe o tratamento equitativo (CIEGIS; RAMANAUSKIENE; MARTINKUS, 2009) entre as dimensões do TBL, quais sejam, a econômica, a social e a ambiental (ELKINGTON, 2012). Esta afirmativa apresenta uma conotação prescritiva ao enfatizar que o lucro deve ser distribuído, contemplando, desta forma, vertente normativa da sustentabilidade (OSÓRIO; LOBATO; CASTILHO, 2005) e à moral da integridade (SROUR, 1994), que caracteriza o comportamento esperado.

Já a afirmativa 16 também contempla as dimensões do TBL (ELKINGTON, 2012), porém, indica que o tratamento equitativo entre as três dimensões (CIEGIS; RAMANAUSKIENE; MARTINKUS, 2009) não se materializa, pois o stakeholder acionista receberia um tratamento privilegiado e os demais seriam negligenciados pela prática organizacional cotidiana. Diferentemente da afirmativa 1, esta afirmativa não possui conotação prescritiva, pelo contrário, ancora-se na vertente positiva da sustentabilidade (OSÓRIO; LOBATO; CASTILHO, 2005) e à moral do oportunismo (SROUR, 1994), que caracteriza o comportamento efetivo.

Do ponto de vista metodológico, espera-se que o respondente que concorde com a afirmativa 1, assuma uma posição de discordância em relação à afirmativa 16. Caso isso ocorra, haverá um indicativo da existência de alinhamento entre o comportamento esperado e o comportamento efetivo no sentido da existência de tratamento equitativo das três dimensões do TBL (CIEGIS; RAMANAUSKIENE; MARTINKUS, 2009; ELKINGTON, 2012). Porém caso haja uma concordância e/ou discordância em ambas as afirmativas 1 e 16, haverá um indicativo de falta de alinhamento entre o comportamento esperado e o comportamento efetivo.

A população de interesse do estudo foi a de alunos da graduação em ciências contábeis de uma universidade pública federal localizada na região sudeste do Brasil. O curso funciona nos turnos matutino e noturno e a amostra da pesquisa contou com 285 respondentes $(36,12 \%$ do total da população de 789 discentes vinculados ao curso) que estavam distribuídos em todos os períodos do curso (PD-I1; PD-I2; PD-I3). Considerando a aleatoriedade do método de amostragem, pôdese inferir por meio de um cálculo para populações finitas que os resultados da pesquisa possuem um nível de confiança de 95\% com uma margem de erro de 4,5\% (LEVINE et al., 2015). 
Para testar a confiabilidade do questionário, especialmente em relação aos construtos abordados nos blocos de afirmativas relativos ao "comportamento esperado" e ao "comportamento efetivo", utilizou-se alfa de cronbach e a análise fatorial pelo método de análise de componentes principais. O alfa de cronbach para o conjunto de afirmativas que caracterizavam o comportamento esperado foi de 0,862 . O alfa de cronbach para o conjunto de afirmativas que caracterizavam o comportamento efetivo foi de 0,881 . Considerando que ambos foram superiores a 0,7 , pode-se inferir que todos os construtos apresentaram um adequado nível de confiabilidade (FÁVERO et al., 2009).

A respeito da análise fatorial exploratória, observou-se que a estatística KMO (KaiserMeyer-Olkin) apresentou o valor de 0,886. Conforme Fávero et al. (2009), este valor pode ser considerado adequado para a utilização desta técnica. Adicionalmente, o teste de esfericidade de Barlett foi significativo a $1 \%(\mathrm{p}=0,000)$, aspecto que também sugere a adequação da análise fatorial, segundo Fávero et al. (2009). Dez fatores puderam ser extraídos com autovalores maiores que 1. Porém, ao se observar o gráfico Scree apresentado na Figura 2, pode-se notar que dois deles possuem uma capacidade de explicação da variância total consideravelmente maior que os demais, embora um terceiro fator também poderia ser observado como relevante. No entanto, presume-se que os dois fatores mais representativos caracterizem os construtos "comportamento esperado" e "comportamento efetivo".

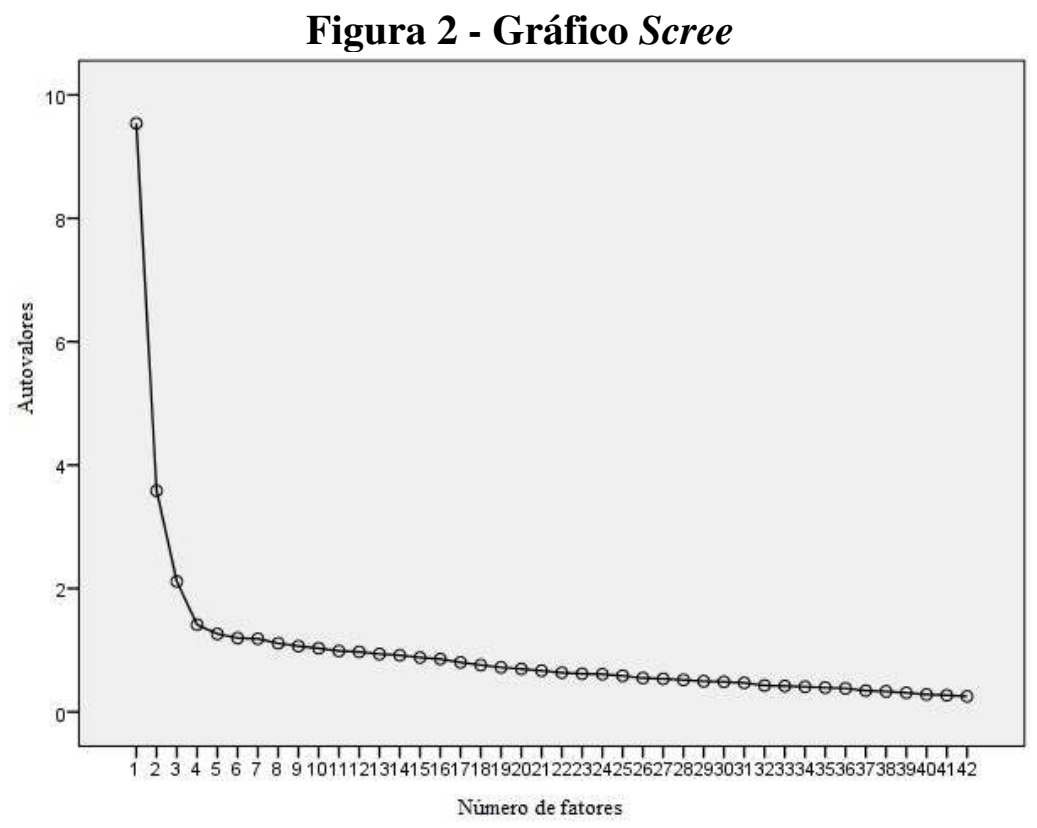

Fonte: dados da pesquisa.

Após a observação de que dois fatores seriam mais relevantes para a explicação do total da variância, procedeu-se à análise fatorial para a identificação de dois fatores. A partir da matriz de componente rotativa dessa análise fatorial (método varimax com rotação ortogonal), verificou-se a adequação dos itens dos questionários aos construtos esperados. $\mathrm{O}$ valor de 0,35 (em valores absolutos) foi utilizado como corte nas cargas fatoriais, visto que a amostra da pesquisa ultrapassou 250 respondentes, valor de corte indicado como adequado para este tamanho amostral (FÁVERO et al., 2009). Do total de 42 itens, 39 (92,85\%) apresentaram carga fatorial maior que 0,35 em valores absolutos. Destes 39 itens, 36 (85,71\% do total de 42 itens) se associaram corretamente com o fator esperado na elaboração do questionário. Considera-se que o percentual de acerto na associação dos itens caracterize uma adequada confiabilidade para os construtos "comportamento esperado" e "comportamento efetivo". 
Após a identificação da confiabilidade do instrumento de pesquisa, procedeu-se à análise de distribuição de frequências das afirmativas em escala de Likert do tipo verbal (COSTA; ORSINI; CARNEIRO, 2018). Ressalta-se que todos os procedimentos estatísticos foram realizados por meio do software SPSS versão 22.

\section{Apresentação, Análise e Discussão dos Resultados}

Estruturou-se esta seção em três partes. Na primeira parte, são apresentadas as considerações acerca do curso de ciências contábeis. Na segunda apresenta-se os dados sociodemográficos da amostra. Por fim, na terceira parte, aborda-se os resultados da pesquisa.

\subsection{O curso de Ciências Contábeis}

O curso de ciências contábeis da IES foi criado na década de 1960 inicialmente funcionando apenas no turno noturno. No final da década de 2000, o curso passou a ser ofertado também no turno vespertino. Do ponto de vista formal, o curso possui dois PPC, sendo um para o turno vespertino e outro para o noturno. Cada PPC possui definições sobre o perfil do egresso, objetivo do curso, estrutura curricular entre outros aspectos. Em relação ao perfil do egresso, os dois PPC destacam o compromisso do curso em formar profissionais com conhecimentos científicos e técnicos e com sólida formação humanística para enfrentar as demandas do campo empresarial e social, materializando conhecimentos de forma interdisciplinar (PD-I2; PD-I3).

Os PPC têm a mesma definição de perfil de egresso, bem como as mesmas estruturas curriculares para os dois turnos. Em ambos os casos os cursos são compostos por 8 módulos que podem ser integralizados em 4 anos, podendo ser estendidos por no máximo mais dois anos. Destaca-se que segundo a estrutura de gestão universitária da IES, o corpo docente vinculado ao departamento de ciências contábeis atende aos dois turnos e que os discentes do turno matutino podem cursar disciplinas no turno noturno e vice-versa (PD-I1; PD-I2; PD-I3).

Em relação ao foco de interesse nesta pesquisa, que é a oferta de conteúdos relacionados à moral e à ética, à RSC e à sustentabilidade, destaca-se que nos dois turnos, são ofertadas as disciplinas filosofia e ética ( $1^{\circ}$ período), contabilidade social, contabilidade ambiental e contabilidade para instituições sem fins lucrativos (todas como disciplinas optativas no curso). Além dessas disciplinas, os conteúdos relativos às questões socioambientais e de sustentabilidade são tratados em atividades complementares, em projetos de extensão e de pesquisa (PD-I2; PDI3).

Assim, com base na pesquisa documental, foi possível observar que o PPC de ciências contábeis atende às normas regulatórias da educação superior brasileira para a formação educacional e profissional em ciências contábeis (PD-N1; PD-N2; PD-N3). Nesse sentido, os discentes do curso de ciências contábeis da IES investigada, ao concluírem o curso, atenderão aos requisitos legais para inscrição junto ao $\mathrm{CRC}$ e poderem exercer a profissão contábil em todo o território nacional brasileiro.

Considerando as características do curso, da estrutura de gestão universitária da IES, do perfil do egresso definido nos PPC e o objeto de investigação da pesquisa, optou-se neste estudo por tratar os dois turnos em conjunto. Com isso, os dados coletados, analisados e apresentados nas próximas subseções e seções do texto serão tratados coletivamente.

\subsection{Dados sociodemográficos}

Apresenta-se nesta subseção aspectos relacionados à população e a amostra da pesquisa, bem como suas características sociodemográficas. Segundo os dados da instituição, há no curso de ciências contábeis 789 discentes matriculados (PD-I1). Levando-se em consideração o tamanho 
da população, o nível de confiança de $95 \%$ e erro amostral de $6 \%$, o tamanho requerido de uma amostra probabilística que permita a generalização dos resultados é de 200 alunos matriculados.

A coleta de dados teve como resultado 285 questionários válidos, sendo este o tamanho da amostra. Assim, ao considerar o tamanho da amostra requerido e o quantitativo de questionários coletados junto a amostragem probabilística, foi possível a generalização dos resultados para toda a população. A Tabela 1 a seguir apresenta a síntese dos resultados dos dados sociodemográficos da amostra investigada.

Tabela 1 - Dados sociodemográficos dos respondentes

\begin{tabular}{|c|c|c|c|c|c|}
\hline \multicolumn{3}{|l|}{ Sexo } & \multicolumn{3}{|c|}{ Possui pós-graduação } \\
\hline Masculino & 142 & $49,8 \%$ & Não & 270 & $94,7 \%$ \\
\hline Feminino & 143 & $50,2 \%$ & Sim (cursando/concluído) & 15 & $5,3 \%$ \\
\hline \multicolumn{3}{|c|}{ Turno } & \multicolumn{3}{|c|}{ Possui atividade profissional } \\
\hline Vespertino & 139 & $48,8 \%$ & Não possui & 96 & $33,7 \%$ \\
\hline Noturno & 146 & $51,2 \%$ & Estagiário & 78 & $27,4 \%$ \\
\hline \multicolumn{3}{|c|}{ Período } & Empregado (Privado) & 70 & $24,6 \%$ \\
\hline Início $\left(1^{\circ}, 2^{\circ}\right.$ e $\left.3^{\circ}\right)$ & 133 & $46,7 \%$ & Empregado/Servidor Público & 31 & $10,9 \%$ \\
\hline $\operatorname{Meio}\left(4^{\circ}, 5^{\circ}\right.$ e $\left.6^{\circ}\right)$ & 98 & $34,4 \%$ & Empresário/Autônomo & 10 & $3,4 \%$ \\
\hline Fim $\left(7^{\circ}, 8^{\circ}\right.$ e $\left.9^{\circ}\right)$ & 54 & $18,9 \%$ & \multicolumn{3}{|c|}{ Já cursou "Moral e Ética" } \\
\hline \multicolumn{3}{|c|}{ Estado civil } & Não & 43 & $15,1 \%$ \\
\hline Solteiro & 234 & $82,1 \%$ & Sim (cursando) & 53 & $18,6 \%$ \\
\hline Casado/convive maritalmente & 51 & $17,9 \%$ & Sim (concluído) & 189 & $66,3 \%$ \\
\hline \multicolumn{3}{|c|}{ Faixa etária } & \multicolumn{3}{|c|}{ Já cursou "Responsabilidade Social" } \\
\hline De 16 até 20 & 81 & $28,4 \%$ & Não & 139 & $48,8 \%$ \\
\hline De 21 até 25 & 130 & $45,6 \%$ & Sim (cursando) & 32 & $11,2 \%$ \\
\hline De 26 até 30 & 35 & $12,3 \%$ & Sim (concluído) & 114 & $40,0 \%$ \\
\hline De 31 até 40 & 24 & $8,4 \%$ & \multicolumn{3}{|c|}{ Já cursou "Sustentabilidade" } \\
\hline Mais de 41 & 15 & $5,3 \%$ & \multirow{4}{*}{$\begin{array}{l}\text { Não } \\
\text { Sim (cursando) } \\
\text { Sim (concluído) }\end{array}$} & 207 & $72,6 \%$ \\
\hline \multicolumn{3}{|c|}{ Possui outro curso de graduação } & & 20 & $7,0 \%$ \\
\hline Não & 246 & $86,3 \%$ & & 58 & $20,4 \%$ \\
\hline Sim (cursando/concluído) & 39 & $13,7 \%$ & & & \\
\hline
\end{tabular}

Fonte: dados da pesquisa.

Pode-se observar que a amostra está bem distribuída entre homens e mulheres e entre os turnos vespertino e noturno. A maior parte dos alunos está no início do curso, seguidos pelos que estão no meio e pelos que estão no fim. Observa-se ainda que a maioria dos alunos já cursou disciplinas que trataram dos temas "moral e ética" e "responsabilidade social", porém a maior parte não cursou a disciplina cujo tema específico fosse a "sustentabilidade". Ao analisar o PPC de ciências contábeis (PD-I2), foi possível constatar a presença da perspectiva legalista (MIRANDA; MIRANDA; ARAÚJO, 2013) e a sua orientação tecnicista (LAFFIN, 2015) que negligencia conteúdos voltados para as questões socioambientais (CARVALHO et al., 2010; TINOCO; ROBLES, 2006). Em parte, este aspecto justifica o baixo número de discentes que tenham cursado disciplinas que abordassem questões relativas à sustentabilidade e às questões ambientais.

\subsection{O ponto de vista dos discentes acerca da sustentabilidade}

As Tabelas 2, 3 e 4 apresentam os resultados das afirmativas sobre a sustentabilidade (CIEGIS; RAMANAUSKIENE; MARTINKUS, 2009) e as dimensões econômica, social e ambiental, do TBL (ELKINGTON, 2012) respectivamente. Para elaboração das afirmativas, foram levados em consideração um conjunto de stakeholders (PURNELL; FREEMAN, 2012) e a relação entre o comportamento esperado e o comportamento efetivo (SROUR, 1994; OSÓRIO; LOBATO; 
CASTILHO, 2005).

Ressalta-se que os pontos 1 e 2 da escala de Likert do tipo verbal (COSTA; ORSINI; CARNEIRO, 2018) foram agrupados para representarem a noção de discordância, enquanto que os pontos 4 e 5 foram agrupados para representarem a noção de concordância. Dessa forma, o percentual de respondentes que assinalou o ponto 3 da escala de Likert do tipo verbal, que representa uma posição de indecisão quanto às afirmativas, não está presente nas tabelas. No entanto, pode-se auferir esse percentual por meio da diferença entre 100\% e a soma dos percentuais dos respondentes que concordam e que discordam com as afirmativas. Este procedimento de somar os dois valores acima do ponto intermediário e os dois valores abaixo do ponto intermediário da escala de 5 pontos representam, respectivamente, o percentual de indicação positiva e negativa em relação à concordância ou à discordância com as afirmativas apresentadas no questionário (COSTA; ORSINI; CARNEIRO, 2018).

A Tabela 2 apresenta afirmativas sobre a dimensão econômica do TBL (ELKINGTON, 2012). O interesse é abordar aspectos à lucratividade, à produtividade e o retorno para os acionistas, entre outras questões relativas à dimensão econômica (ELKINGTON, 2012; CIEGIS; RAMANAUSKIENE; MARTINKUS, 2009).

Tabela 2 - Afirmativas acerca da dimensão econômica do triple bottom line

\begin{tabular}{|c|c|c|c|}
\hline \multicolumn{4}{|c|}{ Painel A } \\
\hline Stakeholder & $\begin{array}{c}\text { Afirmativas que representam o comportamento } \\
\text { esperado }\end{array}$ & Discordam & Concordam \\
\hline Acionistas & $\begin{array}{l}\text { 1. O lucro de uma organização deve sempre ser distribuído } \\
\text { de forma equitativa entre os acionistas, os trabalhadores, } \\
\text { a sociedade e o meio ambiente. }\end{array}$ & $28,07 \%$ & $50,53 \%$ \\
\hline Empregados & $\begin{array}{l}\text { 15. A prática de distribuição de lucros para a classe } \\
\text { trabalhadora deve ser vista como um meio de justiça } \\
\text { social. }\end{array}$ & $17,19 \%$ & $58,60 \%$ \\
\hline Fornecedores & $\begin{array}{l}\text { 38. As organizações devem estabelecer relações } \\
\text { comerciais com fornecedores que sejam benéficas para } \\
\text { ambas as partes. }\end{array}$ & $7,37 \%$ & $78,25 \%$ \\
\hline Consumidores & $\begin{array}{l}\text { 28. Os consumidores devem ser vistos pelas organizações } \\
\text { como parceiros no desenvolvimento de soluções } \\
\text { vantajosas e a preço justo para ambas as partes. }\end{array}$ & $9,82 \%$ & $72,28 \%$ \\
\hline Concorrentes & $\begin{array}{l}\text { 32. As organizações devem estabelecer relações } \\
\text { mercadológicas cooperativas com a concorrência de } \\
\text { forma que todos possam atuar no mercado. }\end{array}$ & $14,39 \%$ & $54,39 \%$ \\
\hline Sociedade & $\begin{array}{l}\text { 30. O principal objetivo organizacional é gerar riqueza } \\
\text { para a sociedade, mesmo que tenha que privar o acionista } \\
\text { de lucros maiores. }\end{array}$ & $41,40 \%$ & $33,68 \%$ \\
\hline Meio Ambiente & $\begin{array}{l}\text { 42. Entre remunerar melhor os acionistas e adotar medidas } \\
\text { de proteção ambiental, as organizações devem privilegiar } \\
\text { investimentos que avancem em direção aos interesses } \\
\text { ambientais. }\end{array}$ & $14,04 \%$ & $67,37 \%$ \\
\hline
\end{tabular}

\begin{tabular}{|c|c|c|c|}
\hline \multicolumn{4}{|c|}{ Painel B } \\
\hline Stakeholder & $\begin{array}{c}\text { Afirmativas que representam o comportamento } \\
\text { efetivo }\end{array}$ & Discordam & Concordam \\
\hline Acionistas & $\begin{array}{l}\text { 16. A prática organizacional cotidiana privilegia a } \\
\text { remuneração aos acionistas em detrimento de outras } \\
\text { partes interessadas, como por exemplo, os trabalhadores, } \\
\text { a sociedade e o meio ambiente. }\end{array}$ & $15,44 \%$ & $58,95 \%$ \\
\hline Empregados & $\begin{array}{l}\text { 36. As organizações adotam a prática de distribuição de } \\
\text { lucros como um mecanismo para obter maior } \\
\text { produtividade da classe trabalhadora. }\end{array}$ & $10,88 \%$ & $66,32 \%$ \\
\hline Fornecedores & $\begin{array}{l}\text { 6. Ao estabelecer relações comerciais com os } \\
\text { fornecedores, as organizações adotam políticas } \\
\text { comerciais voltadas para os resultados de curto prazo, que } \\
\text { podem comprometer a sobrevivência do fornecedor. }\end{array}$ & $16,49 \%$ & $44,21 \%$ \\
\hline 107 & 5-8069, UFSC, Florianópolis, v. 16, n. 41, p. 93-116, out. & 2019 & 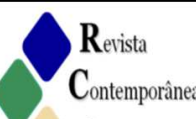 \\
\hline
\end{tabular}




\begin{tabular}{|c|c|c|c|}
\hline Stakeholder & $\begin{array}{c}\text { Afirmativas que representam o comportamento } \\
\text { efetivo }\end{array}$ & Discordam & Concordam \\
\hline Consumidores & $\begin{array}{l}\text { 13. As relações comerciais entre as organizações e os } \\
\text { consumidores é pautada por uma lógica em que ambas as } \\
\text { partes querem levar vantagem imediata. }\end{array}$ & $18,60 \%$ & $59,65 \%$ \\
\hline Concorrentes & $\begin{array}{l}\text { 41. Um dos principais objetivos das organizações é } \\
\text { eliminar a concorrência para alcançar uma maior fatia do } \\
\text { mercado. }\end{array}$ & $17,89 \%$ & $61,05 \%$ \\
\hline Sociedade & $\begin{array}{l}\text { 9. A sociedade é vista pelas organizações apenas como um } \\
\text { espaço para obter recursos e fornecer produtos e serviços } \\
\text { de forma lucrativa. }\end{array}$ & $20,00 \%$ & $57,54 \%$ \\
\hline Meio Ambiente & $\begin{array}{l}\text { 18. As medidas de proteção ambiental são vistas pelas } \\
\text { organizações como um componente de despesa que } \\
\text { comprometem os lucros corporativos. }\end{array}$ & $18,60 \%$ & $63,16 \%$ \\
\hline
\end{tabular}

Fonte: dados da pesquisa.

A Tabela 3 apresenta as afirmativas sobre a dimensão social do TBL (ELKINGTON, 2012). O foco de interesse envolve o bem-estar social, os direitos humanos, os valores culturais, entre outras questões relativas à dimensão social (ELKINGTON, 2012; CIEGIS; RAMANAUSKIENE; MARTINKUS, 2009).

\section{Tabela 3 - Afirmativas acerca da dimensão social do triple bottom line}

\begin{tabular}{|c|c|c|c|}
\hline \multicolumn{4}{|c|}{ Painel A } \\
\hline Stakeholder & $\begin{array}{c}\text { Afirmativas que representam o comportamento } \\
\text { esperado }\end{array}$ & Discordam & Concordam \\
\hline Acionistas & $\begin{array}{l}\text { 20. As organizações devem incluir interesses de outros } \\
\text { públicos, além de acionistas, em seu planejamento } \\
\text { estratégico. }\end{array}$ & $14,39 \%$ & $67,02 \%$ \\
\hline Empregados & $\begin{array}{l}\text { 2. As organizações devem minimizar os riscos e impactos } \\
\text { aos direitos humanos que causam, como por exemplo, } \\
\text { impactos na saúde e bem-estar de empregados próprios e } \\
\text { terceiros. }\end{array}$ & $5,96 \%$ & $81,05 \%$ \\
\hline Fornecedores & $\begin{array}{l}\text { 27. As organizações não devem comprar bens ou serviços } \\
\text { de fornecedores que violem os direitos humanos. }\end{array}$ & $14,39 \%$ & $71,58 \%$ \\
\hline Consumidores & $\begin{array}{l}\text { 21. Os consumidores devem ter os seus valores, crenças e } \\
\text { símbolos culturais respeitados pelas organizações. }\end{array}$ & $11,58 \%$ & $72,98 \%$ \\
\hline Concorrentes & $\begin{array}{l}\text { 19. As organizações devem disponibilizar para a } \\
\text { concorrência informações sobre a sua estratégia de } \\
\text { investimentos sociais. }\end{array}$ & $27,72 \%$ & $51,58 \%$ \\
\hline Sociedade & $\begin{array}{l}\text { 39. As organizações devem manter iniciativas de diálogo } \\
\text { e engajamento com as partes interessadas (público } \\
\text { interno, governo, ONG e comunidade). }\end{array}$ & $10,53 \%$ & $66,67 \%$ \\
\hline Meio Ambiente & $\begin{array}{l}\text { 37. As organizações devem participar constantemente de } \\
\text { fóruns e encontros promovidos por representantes do } \\
\text { meio ambiente. }\end{array}$ & $10,18 \%$ & $69,12 \%$ \\
\hline
\end{tabular}

\begin{tabular}{|c|c|c|c|}
\hline \multicolumn{4}{|c|}{ Painel B } \\
\hline Stakeholder & $\begin{array}{c}\text { Afirmativas que representam o comportamento } \\
\text { efetivo }\end{array}$ & Discordam & Concordam \\
\hline Acionistas & $\begin{array}{l}\text { 22. Os direcionadores do planejamento estratégico das } \\
\text { organizações estão baseados nos interesses dos acionistas. } \\
\text { 10. Os riscos e impactos na saúde e bem-estar de }\end{array}$ & $11,58 \%$ & $65,96 \%$ \\
\hline Empregados & $\begin{array}{l}\text { empregados próprios e terceiros são sempre gerenciados } \\
\text { de forma a minimizar os custos operacionais. }\end{array}$ & $15,44 \%$ & $54,39 \%$ \\
\hline Fornecedores & $\begin{array}{l}\text { 12. Os fornecedores são contratados pela lógica do menor } \\
\text { preço, mesmo que tenham práticas que violem os direitos } \\
\text { humanos. }\end{array}$ & $30,53 \%$ & $50,18 \%$ \\
\hline Consumidores & $\begin{array}{l}\text { 4. As organizações procuram impor seus valores, crenças } \\
\text { e símbolos culturais aos consumidores como uma } \\
\text { estratégia de fidelização de clientes. }\end{array}$ & $20,35 \%$ & $56,14 \%$ \\
\hline
\end{tabular}


A sustentabilidade na perspectiva de discentes de graduação em Ciências Contábeis: prevalece a lógica oportunista e utilitarista

\begin{tabular}{|c|c|c|c|}
\hline Stakeholder & $\begin{array}{c}\text { Afirmativas que representam o comportamento } \\
\text { efetivo }\end{array}$ & Discordam & Concordam \\
\hline Concorrentes & $\begin{array}{l}\text { 29. As organizações não divulgam informações sobre } \\
\text { investimentos sociais por receio de serem imitadas ou } \\
\text { superadas pela concorrência. }\end{array}$ & $26,32 \%$ & $48,42 \%$ \\
\hline Sociedade & $\begin{array}{l}\text { 35. As organizações se relacionam com as partes } \\
\text { interessadas (público interno, governo, ONG e } \\
\text { comunidade) de forma a obter vantagem econômica nessa } \\
\text { relação. }\end{array}$ & $14,74 \%$ & $62,46 \%$ \\
\hline Meio Ambiente & $\begin{array}{l}\text { 24. O meio ambiente é visto pelas organizações somente } \\
\text { como uma fonte de recursos naturais para viabilizar suas } \\
\text { ações produtivas e comerciais. }\end{array}$ & $16,84 \%$ & $60,35 \%$ \\
\hline
\end{tabular}

Fonte: dados da pesquisa.

A Tabela 4 apresenta afirmativas sobre a dimensão ambiental do TBL (ELKINGTON, 2012). O interesse é abordar aspectos relacionados ao meio ambiente, à natureza e aos ecossistemas locais e outras questões relativas à dimensão ambiental (ELKINGTON, 2012; CIEGIS; RAMANAUSKIENE; MARTINKUS, 2009).

Tabela 4 - Afirmativas acerca da dimensão ambiental do triple bottom line

\begin{tabular}{|c|c|c|c|}
\hline \multicolumn{4}{|c|}{ Painel A } \\
\hline Stakeholder & $\begin{array}{c}\text { Afirmativas que representam o comportamento } \\
\text { esperado }\end{array}$ & Discordam & Concordam \\
\hline Acionistas & $\begin{array}{l}\text { 34. As questões ambientais devem ser tratadas com o } \\
\text { mesmo nível de atenção que o lucro é tratado pelos } \\
\text { acionistas. }\end{array}$ & $9,47 \%$ & $74,74 \%$ \\
\hline Empregados & $\begin{array}{l}\text { 31. As organizações devem implementar práticas de } \\
\text { recursos humanos orientadas para a questão ambiental. }\end{array}$ & $9,82 \%$ & $70,53 \%$ \\
\hline Fornecedores & $\begin{array}{l}\text { 3. As organizações devem dar preferência à compra de } \\
\text { insumos ou serviços ambientalmente sustentáveis. }\end{array}$ & $9,47 \%$ & $75,09 \%$ \\
\hline Consumidores & $\begin{array}{l}\text { 8. As organizações devem lançar medidas para incentivar } \\
\text { e sensibilizar o consumidor a encaminhar os resíduos } \\
\text { gerados para reciclagem de volta para as organizações. }\end{array}$ & $11,58 \%$ & $74,74 \%$ \\
\hline Concorrentes & $\begin{array}{l}\text { 23. As organizações devem promover parcerias com os } \\
\text { concorrentes para preservar o meio ambiente. }\end{array}$ & $13,33 \%$ & $66,67 \%$ \\
\hline Sociedade & $\begin{array}{l}\text { 26. As organizações devem incentivar a sociedade no } \\
\text { desenvolvimento de uma cultura ambientalmente } \\
\text { sustentável. }\end{array}$ & $7,72 \%$ & $78,25 \%$ \\
\hline Meio Ambiente & $\begin{array}{l}\text { 11. As organizações devem adotar políticas de proteção e } \\
\text { preservação ambiental em todas as suas atividades. }\end{array}$ & $10,53 \%$ & $\mathbf{7 7 , 8 9 \%}$ \\
\hline \multicolumn{4}{|c|}{ Painel B } \\
\hline Stakeholder & $\begin{array}{c}\text { Afirmativas que representam o comportamento } \\
\text { efetivo }\end{array}$ & Discordam & Concordam \\
\hline Acionistas & $\begin{array}{l}\text { 7. As questões ambientais somente são consideradas se } \\
\text { não houver o comprometimento da lucratividade para o } \\
\text { acionista. }\end{array}$ & $24,56 \%$ & $57,54 \%$ \\
\hline Empregados & $\begin{array}{l}\text { 40. As políticas e práticas de recursos humanos adotadas } \\
\text { pelas organizações alcançam a questão ambiental desde } \\
\text { que não comprometam a produtividade. }\end{array}$ & $15,44 \%$ & $\mathbf{5 7 , 8 9 \%}$ \\
\hline Fornecedores & $\begin{array}{l}\text { 33. Os fornecedores são contratados pela lógica do menor } \\
\text { preço, mesmo que comprometam o meio ambiente. }\end{array}$ & $22,11 \%$ & $54,04 \%$ \\
\hline Consumidores & $\begin{array}{l}\text { 17. Para viabilizar o menor preço para os consumidores, } \\
\text { as organizações reduzem investimentos de natureza } \\
\text { ambiental. }\end{array}$ & $17,19 \%$ & $\mathbf{5 7 , 8 9 \%}$ \\
\hline Concorrentes & $\begin{array}{l}\text { 5. Entre vencer a concorrência e ser ambientalmente } \\
\text { sustentável, as organizações optam pela liderança de } \\
\text { mercado. }\end{array}$ & $9,47 \%$ & $69,47 \%$ \\
\hline
\end{tabular}




\begin{tabular}{|c|c|c|c|}
\hline Stakeholder & $\begin{array}{c}\text { Afirmativas que representam o comportamento } \\
\text { efetivo }\end{array}$ & Discordam & Concordam \\
\hline Sociedade & $\begin{array}{l}\text { 25. As organizações investem em políticas ambientais } \\
\text { que favorecem a sociedade somente se houver retorno } \\
\text { financeiro. }\end{array}$ & $19,30 \%$ & $61,05 \%$ \\
\hline Meio Ambiente & $\begin{array}{l}\text { 14. As organizações somente adotam medidas corretivas } \\
\text { quando causam impactos ambientais negativos. }\end{array}$ & $14,04 \%$ & $68,07 \%$ \\
\hline
\end{tabular}

Fonte: dados da pesquisa.

A análise conjunta dos resultados apresentados nas Tabelas 2, 3 e 4 indica que, de uma forma geral, os respondentes têm uma noção de sustentabilidade e das dimensões econômica, social e ambiental que se modifica quando se observa o comportamento esperado (lógica da moral da integridade e a vertente normativa do conceito de sustentabilidade) e o comportamento efetivo (lógica da moral do oportunismo a vertente positiva do conceito de sustentabilidade) (SROUR, 1994; OSÓRIO; LOBATO; CASTILHO, 2005). Sob o ponto de vista do comportamento esperado os respondentes assumem que as dimensões econômicas, social e ambiental de sustentabilidade são tratadas de forma equitativa, considerando a perspectiva de longo prazo por envolver as gerações futuras (ELKINGTON, 2012; CIEGIS; RAMANAUSKIENE; MARTINKUS, 2009; PIERANTONI, 2004). Já sob o ponto de vista do comportamento efetivo, os respondentes consideram que há uma hierarquia entre as dimensões de sustentabilidade em que a dimensão econômica prevalece sob as demais. A prevalência da dimensão econômica pode ser observada pelo fato de as afirmativas dos blocos relativos ao comportamento efetivo (dimensões econômica, social e ambiental) (1) enfatizarem que a dimensão econômica prevalece sobre as demais; e (2) apresentarem sempre os maiores percentuais de concordância por parte dos respondentes.

Diante de tais resultados, é relevante refletir sobre as possíveis explicações desta duplicidade moral tipicamente brasileira (SROUR, 1994). Em termos do comportamento esperado, é possível que os respondentes tenham sofrido influências do "discurso politicamente correto" da sustentabilidade corporativa que permeia a sociedade contemporânea, sobretudo em termos da lógica de cooperação que visa resultados de longo prazo e para um grupo maior de stakeholders (ELKINGTON, 2012; CIEGIS; RAMANAUSKIENE; MARTINKUS, 2009).

Já em termos do comportamento efetivo, há um indicativo de influências da "pedagogia das competências" que pressupõe um viés tecnicista da formação em ciências contábeis (LAFFIN, 2015; PADOAN; CLEMENTE, 2006), bem como da perspectiva legalista inerente a atividade profissional do contador (MIRANDA; MIRANDA; ARAÚJO, 2013), ao caráter eminentemente utilitarista presente na disciplina contábil (IUDÍCIBUS; MARTINS; CARVALHO, 2005) e as influências que a teoria positiva da contabilidade (WATTS; ZIMMERMAN, 1986) exercem sob a formação de discentes de ciências contábeis. Soma-se a esses indicativos o fato de que, como destacam Carvalho et al. (2010) e Tinoco e Robles (2006), os cursos de ciências contábeis têm negligenciado em seus PPC os conteúdos voltados para as questões socioambientais.

No conjunto, estas características típicas da formação contábil e na estrutura curricular (PD-I2) são responsáveis por induzir os discentes a assumirem prioritariamente o aspecto econômico e financeiro nas relações sociais (LAFFIN, 2015). Com isso, a noção de sustentabilidade apontada por Elkington (2012) e Ciegis, Ramanauskiene e Martinkus (2009) fica comprometida pelo fato de a lógica oportunista e utilitarista (IUDÍCIBUS; MARTINS; CARVALHO, 2005; WATTS; ZIMMERMAN, 1986) imperar no processo de formação educacional e profissional do futuro contador.

\section{Conclusões}

Pretendeu-se com este estudo identificar o ponto de vista de discentes em ciências contábeis acerca da noção de sustentabilidade. Para isso, aplicou-se uma pesquisa survey 
(BABBIE, 2005) junto aos discentes do curso de graduação de uma universidade pública federal localizada na região sudeste do Brasil. Os dados foram coletados por meio de triangulação (DENZIN, 1989) ao articular pesquisa documental e aplicação de questionário junto a uma amostra probabilística de 233 discentes matriculados nos turnos matutino e noturno.

A síntese dos resultados indica que a noção de sustentabilidade se altera quando se observa o comportamento esperado e o comportamento efetivo (SROUR, 1994). Enquanto que o comportamento esperado indica que a sustentabilidade trata de forma equitativa as dimensões econômica, social e ambiental (ELKINGTON, 2012; CIEGIS; RAMANAUSKIENE; MARTINKUS, 2009), o comportamento efetivo indica que a sustentabilidade possui uma lógica oportunista e utilitarista (IUDÍCIBUS; MARTINS; CARVALHO, 2005; WATTS; ZIMMERMAN, 1986, 1990; WATTS, 1992) que privilegia a dimensão econômica em detrimento das demais.

Os resultados indicam para a necessidade de se repensar o processo de formação educacional e profissional na área das ciências contábeis, bem como a forma como a sustentabilidade tem sido tratada nos cursos de ciências contábeis. As evidências apontadas na pesquisa estão alinhadas com as constatações encontradas em estudos anteriores na literatura internacional (LEE, 1989; HUMPHREY; LEWIS; OWEN, 1996; MATHEWS, 2001; GRAY; COLLISON, 2002) sobre as necessárias e urgentes mudanças na estrutura da formação superior contábil, no que tange à inserção e vivência dos conteúdos socioambientais, visando a uma atuação profissional dos egressos que seja efetivamente transformadora para a sociedade. De forma semelhante, no contexto brasileiro, Laffin (2015), Carvalho et al. (2010) e Tinoco e Robles (2006) apontam para a necessidade de abandonar o modelo da "pedagogia das competências" com viés tecnicista e redirecionar a formação do contador rumo a um viés científico e colaborativo que se preocupe com questões socioambientais e sobretudo relacionadas à sustentabilidade e ao desenvolvimento sustentável.

Com isso, defende-se neste artigo a necessidade de que a sustentabilidade seja tratada nos cursos de ciências contábeis de forma transversal e transdisciplinar e por meio de uma abordagem holística, de integração e de síntese (VASCONCELOS; SILVA JUNIOR, SILVA, 2013; SENGE et al., 2009; ALMEIDA, 2008). Com isso, o processo de ensino e a aprendizagem produzirá resultados diferentes no ponto de vista dos discentes de ciências contábeis. Esta diferença tende a privilegiar a perspectiva sustentável em detrimento da perspectiva oportunista e utilitarista (IUDÍCIBUS; MARTINS; CARVALHO, 2005; WATTS; ZIMMERMAN, 1986, 1990; WATTS, 1992).

A presente pesquisa apresenta limitações, das quais pode-se destacar (1) a investigação de um único curso de ciências contábeis de uma única IES; (2) a adoção de uma abordagem metodológica descritivo-quantitativa por meio de um survey: e (3) ter optado por coletar dados junto a apenas duas fontes, quais sejam, os estudantes e os documentos. Como forma de superar estas limitações, sugere-se como possibilidades de estudos posteriores a investigação, por meio do recorte de pesquisa descritivo-quantitativo do tipo survey, junto a outros cursos e IES brasileiras. Uma outra possibilidade seria o aprofundamento da investigação, por meio de pesquisa qualitativa, junto ao mesmo curso e IES investigada, inclusive ampliando as fontes de informações para incluir docentes e coordenadores como forma de compreender melhor os resultados encontrados.

Espera-se que os resultados aqui apresentados possam indicar caminhos para que gestores universitários, gestores de políticas públicas e empresários reflitam sobre a necessidade de adotar uma visão e abordagem para a sustentabilidade em que a perspectiva holística, de integração e de síntese norteie o processo de formação educacional nos cursos de graduação em ciências contábeis, inclusive na postura das instituições, de forma a se refletir nas tomadas e decisões de negócios posteriormente. Considera-se essas questões essenciais para a construção de uma sociedade melhor, mais justa, socialmente responsável e sustentável. 


\section{Referências}

ALMEIDA, F. Os desafios da sustentabilidade: uma ruptura urgente. Rio de Janeiro: Campus Elsevier, 2008.

ARANHA, M. L.; MARTINS, M. H. Filosofando: introdução à filosofia. 3. ed. São Paulo: Moderna, 2005.

BABBIE, E. Métodos de pesquisas de survey. Belo Horizonte: Editora UFMG, 2005.

BELL, S.; MORSE, S. Sustainability indicators: measuring the immeasurable? 2nd. ed. London: Earthscan, 2008.

BRASIL Decreto-Lei no 9.295, de 27 de maio de 1946. Cria o Conselho Federal de Contabilidade, define as atribuições do Contador e do Guarda-livros, e dá outras providências. Diário Oficial da República Federativa do Brasil, seção 1, Brasília, DF, p. 7889, 28 mai. 1946.

BRASIL. Lei no 9.394 de 20 de dezembro de 1996. Estabelece as diretrizes e bases da educação nacional. Diário Oficial da União: seção 1, Brasília, DF, p. 27839, 23 dez. 1996.

CABRAL, N. L. S. C. Discurso, interdição e liberdade de expressão: o politicamente correto e suas articulações com a comunicação social. In: INTERPROGRAMAS DE MESTRADO DA FACULDADE CÁSPER LÍBERO, 14., 2013, São Paulo. Anais [...]. São Paulo: Faculdade Cásper Líbero, 2013.

CARVALHO, J. R. M.; ALEXANDRE, F. A. M.; ALMEIDA, K. K. N.; CARVALHO, E. K. M. A.; CURI, W. F. Uma análise do interesse dos estudantes de ciências contábeis pela área de contabilidade ambiental. Revista Ambiente Contábil, Natal, v. 2, n. 1, p, 37-53, 2010.

CIEGIS, R.; RAMANAUSKIENE, J.; MARTINKUS, B. The concept of sustainable development and its use for sustainability scenarios. Engineering Economics, [S.l.], v. 62, n. 2, p. 28-37, 2009.

\section{COMISSÃO MUNDIAL SOBRE MEIO AMBIENTE E DESENVOLVIMENTO. Nosso futuro} comum. 2 ed. Rio de Janeiro: Editora da Fundação Getúlio Vargas, 1991.

CONSELHO NACIONAL DA EDUCAÇÃO. Resolução nº 10, de 16 de dezembro de 2004. Institui as Diretrizes Curriculares Nacionais para o Curso de Graduação em Ciências Contábeis, bacharelado, e dá outras providências. Diário Oficial da República Federativa do Brasil, seção 1, Brasília, DF, p. 15, 28 dez. 2004.

COSTA, F. J.; ORSINI, A. C. R.; CARNEIRO, J. S. Variações de mensuração por tipos de escalas de verificação: uma análise do construto de satisfação discente. Revista Eletrônica de Gestão Organizacional, Recife, v. 16, n. 2, p. 132-144, 2018. http://dx.doi.org/10.21714/167918272018v16n2.p132-144

DENZIN, N. The research act: a theoretical introduction to sociological methods. 3. ed. New York, NY: Prentice Hall, 1989. 
ELKINGTON, J. Sustentabilidade: canibais com garfo e faca. São Paulo: MBooks, 2012.

FACCI, N. Ética e responsabilidade social: desafios constantes para a controladoria. In:

CONGRESSO BRASILEIRO DE CUSTOS, 9., 2002, São Paulo. Anais [...]. São Leopoldo/RS: Associação Brasileira de Custos, 2002.

FÁVERO, L. P.; BELFIORE, P.; SILVA, F. L.; CHAN, B. L. Análise de dados: modelagem multivariada para tomada de decisões. Rio de Janeiro: Elsevier, 2009.

GRAY, R.; BEBBINGTON, J.; McPHAIL, K. Teaching ethics and the ethics of accounting teaching: educating for immorality and a case for social and environmental accounting education. Accounting Education, [S.l.], v. 3, n. 1, p. 51-75, 1994. https://doi.org/10.1080/09639289400000005

GRAY, R.; COLLISON, D. Can't see the wood for the trees, can't see the trees for the numbers? accounting education, sustainability and the public interest. Critical Perspectives in Accounting, [S.l.], v. 13, n. 1, p. 797-836, 2002. https://doi.org/10.1006/cpac.2002.0554

HANN, T.; PINKSE, J.; PREUSS, L.; FIGGE, F. Tensions in corporate sustainability: towards an integrative framework. Journal of Business Ethics, [S.l.], v. 127, n. 2, p. 297-316, 2015. https://doi.org/10.1007/s10551-014-2047-5

HUMPHREY, C.; LEWIS, L.; OWEN, D. Still too distant voices? conversations and reflections on the social relevance of accounting education. Critical Perspectives in Accounting, [S.l.], v. 7, n. 1, p. 77-99, 1996. https://doi.org/10.1006/cpac.1996.0010

IUDÍCIBUS, S.; MARTINS, E.; CARVALHO, L. N. Contabilidade: aspectos relevantes da epopéia de sua evolução. Revista Contabilidade \& Finanças, São Paulo, v. 16, n. 38, p. 7-19, 2005. https://doi.org/10.1590/S1519-70772005000200002

JICK, T. D. Mixing quantitative and qualitative methods: triangulation and action.

Administrative Science Quarterly, [S.l.], v. 24, n. 4, p. 602-611, 1979. https://doi.org/10.2307/2392366

LAFFIN, M. Graduação em ciências contábeis - a ênfase nas competências: contribuições ao debate. Arquivos Analíticos de Políticas Educativas, [S.l.], v. 23, n. 78, p. 1-30, 2015. http://dx.doi.org/10.14507/epaa.v23.1844

LEE, T. Education, practice and research in accounting: gaps, closed loops, bridges and magic accounting. Accounting and Business Research, [S.l.], v. 19, n. 75, p. 237-253, 1989. https://doi.org/10.1080/00014788.1989.9728854

LÉLÉ, S. Sustainable development: a critical review. World Development, [S.l.], v. 19, n. 6, p. 607-621, 1991. https://doi.org/10.1016/0305-750X(91)90197-P

LEVINE, D.; STEPHAN, D. F.; KREHBLEL, T.; BERENSON, M. L. Estatística: teoria e aplicações 6. ed. Rio de Janeiro: LTC, 2015.

MACIEL, C. V.; LAGIOIA, U. C. T.; LIBONATI, J. J.; RODRIGUES, R. N. Contabilidade Ambiental: um estudo exploratório sobre o conhecimento dos profissionais de contabilidade. 
Revista Contemporânea de Contabilidade. Florianópolis, v.1, n. 11, p. 137-158, 2009. https://doi.org/10.5007/2175-8069.2009v6n11p137

MARTIN, N. C. Da contabilidade à controladoria: a evolução necessária. Revista Contabilidade \& Finanças, São Paulo, n. 28, p. 7-28, 2002. https://doi.org/10.1590/S151970772002000100001

MATHEWS, M. R. Some thoughts on social and environmental accounting education. Accounting Education: An International Journal, [S.l.], v. 10, n. 4, p. 335-352, 2001. https://doi.org/10.1080/09639280210121132

MEBRATU, D. Sustainability and sustainable development: historical and conceptual review. Environmental Impact Assessment Review, [S.l.], v. 18, n. 6, p. 493-520, 1998. https://doi.org/10.1016/S0195-9255(98)00019-5

MIRANDA, C. S.; MIRANDA, R. A. M.; ARAÚJO, A. M. P. Percepções dos estudantes do ensino médio sobre o curso de ciências contábeis e as atividades do profissional contador.

Revista de Gestão, Finanças e Contabilidade, [S.l.], v. 3, n. 1, p. 17-35, 2013. http://dx.doi.org/10.18028/rgfc.v3i1.105

MIRANDA, G. J.; CASA NOVA, S. P. de C.; CORNACCHIONE JÚNIOR, E. B. Os saberes dos professores-referência no ensino de contabilidade. Revista Contabilidade \& Finanças, São Paulo, v. 23, n. 59, p. 142-153, 2012. https://doi.org/10.1590/S1519-70772012000200006

MOGALAKWE, M. The use of documentary research methods in social research. African Sociological Review, [S.l.], v. 10, n. 1, p. 221-230, 2006.

MOTKE, F. D.; ROSA, L. A. B.; LENGLER, L.; MAINARDI, J.; TREVISAN, M. Valores de consumo para a sustentabilidade: um estudo com os acadêmicos do curso de ciências contábeis da Universidade Federal de Santa Maria. Revista de Administração da UFSM, Santa Maria, v. 9, ed. especial, p. 107-121, 2016. http://dx.doi.org/10.5902/1983465921918

MUNCK, L.; SOUZA, R. B. O ecletismo do paradigma da sustentabilidade: construção e análise a partir dos estudos organizacionais. Revista de Ciências da Administração, Florianópolis, v. 13, n. 29, p. 202-242, 2011. https://doi.org/10.5007/2175-8077.2011v13n29p202

OSORIO, L. A. R.; LOBATO, M. O.; CASTILLO, X. A. Debates on sustainable development: towards a holistic view of reality. Environment, Development and Sustainability, [S.l.], v. 7, p. 501-518, 2005. https://doi.org/10.1007/s10668-004-5539-0

PADOAN, F.; CLEMENTE, A. A interdisciplinaridade no ensino da contabilidade: um estudo empírico da percepção dos docentes. In: CONGRESSO USP DE CONTABILIDADE E

CONTROLADORIA, 6., 2006, São Paulo. Anais [...]. São Paulo: USP, 2006.

PALETTA, F. C. O papel do educador na formação do profissional da informação e os desafios da cidadania responsável. Cadernos de Educação, Tecnologia e Sociedade, Inhumas, v.9, n.2, p. 127-138, 2016. http://dx.doi.org/10.14571/cets.v9.n2.127-138

PEDRO, A. P. Ética, moral, axiologia e valores: confusões e ambiguidades em torno de um conceito comum. Kriterion: Revista de Filosofia, Belo Horizonte, v. 55, n. 130, p. 483-498, 
2014. https://doi.org/10.1590/S0100-512X2014000200002

PIERANTONI, I. A. Few remarks on methodological aspects related to sustainable development. In: OECD. Measuring sustainable development: integrated economic, environmental and social frameworks. [S.l.]: OECD Publishing. 2004. p. 63-89.

PIRES, C. B.; OTT, E.; DAMACENA, C. A formação do contador e a demanda do mercado de trabalho na Região Metropolitana de Porto Alegre (RS). BASE: Revista de Administração e Contabilidade da Unisinos, São Leopoldo, v. 7, n. 4, p. 315-327, 2010.

https://doi.org/10.4013/base.2010.74.05

PURNELL, L. S.; FREEMAN, R. E. Stakeholder theory, fact/value dichotomy, and the normative core: how Wall Street stop the ethics conversation. Journal of Business Ethics, [S.1], v. 109, p. 109-116, 2012. https://doi.org/10.1007/s10551-012-1383-6

RAIA, F. S.; MELZ, L. J. Percepção dos discentes e docentes sobre estágio supervisionado no curso de ciências contábeis da UNEMAT - campus de Tangará da Serra. Revista

Contemporânea de Contabilidade. Florianópolis, v.8, n. 16, p. 111-136, 2011.

https://doi.org/10.5007/2175-8069.2011v8n16p111

RODRIGUES, T. C.; MACHADO, D. G.; COSTA, A. A. da; SOUZA, M. A. de.

Desenvolvimento sustentável: percepção dos alunos do curso de graduação em ciências contábeis das Instituições Federais de Ensino Superior do Estado do Rio Grande do Sul. Revista Metropolitana de Sustentabilidade, São Paulo, v. 7, n. 1, p. 68-90, 2017.

SCHWARTZ, S. H. An overview of the Schwartz theory of basic values. Online Readings in Psychology and Culture, [S.l.], v. 2, n. 1, p. 2307-0919, 2012. https://doi.org/10.9707/23070919.1116

SENGE, P.; SMITH, B.; KRUSCHWITZ, N.; SCHLEY, S.; LAUR, J. A Revolução decisiva: como indivíduos e organizações trabalham em parceria para criar um mundo sustentável. Tradução de Afonso Celso da Cunha Serra. Rio de Janeiro: Campus Elsevier, 2009.

SILVA, E. C.O.; RÊGO, T. F. Proposta formativa versus desempenho: um estudo comparativo entre os cursos de graduação em ciências contábeis das Ifes brasileiras. Revista Ambiente Contábil. Natal, v.6, n. 2, p. 55-74, 2014.

SILVA JUNIOR, A.; VASCONCELOS, K. C. A.; SILVA, V. C.; MARTINS-SILVA, P. O.; SANTOS. T. C. S.; VAGO, J. G. R. A moral e a ética na perspectiva de discentes de graduação em ciências contábeis de uma universidade pública: entre a integridade e o oportunismo. In: ENCONTRO NACIONAL DA ANPAD, 41., 2017, São Paulo. Anais [...]. Rio de Janeiro: ANPAD, 2017.

SOUZA, A. A.; AVELAR, E. A.; BOINA, T. M.; RODRIGUES, L. T. Ensino da contabilidade gerencial: estudo dos cursos de ciências contábeis das melhores universidades brasileiras.

Revista Contemporânea de Contabilidade. Florianópolis, v.1, n. 10, p. 69-90, 2008. https://doi.org/10.5007/2175-8069.2008v5n10p69

SROUR, R. H. Ética empresarial sem moralismo. Revista de Administração da USP, São Paulo, v. 29, n. 3, p. 3-22, 1994. 
TINOCO, J. E. P.; ROBLES, L. T. A contabilidade da gestão ambiental e sua dimensão para a transparência empresarial: estudo de caso de quatro empresas brasileiras com atuação global. Revista de Administração Pública, Rio de Janeiro, v. 40, n. 6, p. 1077-1096, 2006. https://doi.org/10.1590/S0034-76122006000600008

VASCONCELOS, K. C. de A.; SILVA JUNIOR, A. da; SILVA, P. de O. M. da. Educação gerencial para atuação em ambientes de negócios sustentáveis: desafios e tendências de uma escola de negócios brasileira. Revista de Administração Mackenzie, São Paulo, v. 14, n. 4, p. 45-75, 2013. https://doi.org/10.1590/S1678-69712013000400003

WATTS, R. L.; ZIMMERMAN, J. L. Positive accounting theory. Englewood Cliffs: Prentice Hall, 1986.

ZEFF, S.A. Recent trends in accounting education and research in the USA: some implications for UK academics. British Accounting Review, [S.l.], v. 21, n. 1, p. 159-176, 1989. https://doi.org/10.1016/0890-8389(89)90194-7

* Uma versão preprint do artigo foi apresentada no XVII Colóquio Internacional de Gestão Universitária (CIGU), 2017. 